\title{
Neither NRT aided gradual cessation nor abrupt cessation is superior in producing long-term abstinence: Reconciling conflicting results from two recent meta-analyses
}

\author{
Elias M. Klemperer', Nicola Lindson²
}

\section{Dear Editor,}

Reduction in tobacco smoking before attempting to quit is common (i.e. gradual cessation $)^{1}$, but guidelines for health professionals recommend abrupt smoking cessation $^{2,3}$. We recently completed a Cochrane systematic review and metaanalysis including 22 trials (9219 participants) of gradual versus abrupt smoking cessation and found neither approach produced superior long-term cessation outcomes ( $\mathrm{RR}=1.01 ; 95 \% \mathrm{CI}$ : $\left.0.87-1.17 ; \mathrm{I}^{2}=29 \%\right)$. We found similar results when restricting the analysis to 9 trials of gradual cessation versus abrupt cessation aided by nicotine replacement therapy (NRT) $(\mathrm{RR}=0.91 ; 95 \%$ CI: 0.72-1.16; $\mathrm{I}^{2}=26 \% ; 4359$ participants $)^{4}$. However, Tan et al. ${ }^{5}$ recently published a metaanalysis that concluded abrupt cessation was superior to gradual cessation with the aid of NRT, which contradicts our findings ${ }^{4}$. Tan et al. ${ }^{5}$ report that they restricted their meta-analysis to 3 trials where abstinence was biochemically verified and 'both groups used an equal amount of NRT before and after quitting'. However, two of their three included trials provided NRT to participants before quitting in the gradual but not in the abrupt cessation condition ${ }^{6,7}$, and the third provided more NRT to the gradual than to the abrupt condition in the period before the quit $\mathrm{day}^{8}$. Our meta-analysis of NRT-aided studies included the three trials in the Tan et al. ${ }^{5}$ meta-analysis, plus an additional six trials comparing gradual versus abrupt smoking cessation ${ }^{4}$. Due to the design of the existing trials testing this comparison, neither meta-analysis provided a test of gradual versus abrupt cessation with equivalent pre- and post-quit NRT across conditions.

There are a number of methodological limitations to the Tan et al. ${ }^{5}$ review, two of which were likely to have led to the limited number of studies found eligible for inclusion. First, they only included studies that used biochemically verified abstinence. Although, this is a gold standard for measuring smoking abstinence in trials ${ }^{9}$, and its absence may inflate absolute abstinence rates, there is no apparent reason to assume that the likelihood of misreporting abstinence would differ between the gradual and abrupt conditions. Thus, the use of selfreported abstinence in some trials is unlikely to have affected relative abstinence rates (e.g. risk ratios) and should be included in meta-analyses to maximize the use of existing research. Second, they reported the use of very limited search terms (['smoking cessation'] AND ['abrupt' OR 'gradual']), which appear to have missed much of the relevant literature. Many relevant trials do not use the terms 'gradual' or 'abrupt' to describe their methodology. This is supported by the fact that their searches resulted in 134 records for screening ${ }^{5}$, as opposed to the 1944 records screened by Lindson et al. ${ }^{8}$. Thus, we conclude that due to methodological limitations, the Tan et al. ${ }^{5}$ findings do not fully represent existing research. When all trials of NRT-aided gradual versus abrupt smoking cessation

\section{AFFILIATION \\ 1 Department of Psychiatry, University of Vermont, Burlington, United States 2 Nuffield Department of Primary Care Health Sciences, University of Oxford, Oxford, United Kingdom}

CORRESPONDENCE TO

Elias M. Klemperer. Department of Psychiatry, University of Vermont, UHC Campus, Mailstop $482 \mathrm{OH} 4,1$ S. Prospect St., Burlington, VT 05401, United States. E-mail: elias.klemperer@med.uvm.edu ORCID ID: https://orcid. org/0000-0002-7985-0870

\section{KEYWORDS}

smoking cessation, gradual, abrupt, meta-analysis

Received: 11 October 2019 Accepted: 25 October 2019 
are meta-analyzed, neither approach to quitting is superior in producing long-term abstinence ${ }^{4}$. Therefore, we conclude that people who do not wish to quit smoking abruptly could be encouraged to quit gradually.

\section{REFERENCES}

1. Reid JL, Hammond D, Tariq U, Burkhalter R, Rynard VL, Douglas O. Tobacco Use in Canada: Patterns and Trends, 2019 Edition. Waterloo, ON: Propel Centre for Population Health Impact, University of Waterloo.

2. Clinical Practice Guideline Treating Tobacco Use and Dependence 2008 Update Panel, Liaisons, and Staff. A clinical practice guideline for treating tobacco use and dependence: 2008 update. Am J Prev Med. 2008;35(2):158-176. doi:10.1016/j.amepre.2008.04.009

3. National Institute for Health and Care Excellence. Stop smoking interventions and services. NICE guideline [NG92]. www.nice.org.uk/guidance/ng92. Published March, 2018. Accessed October 9, 2019.

4. Lindson N, Klemperer E, Hong B, Ordonez-Mena JM, Aveyard P. Smoking reduction interventions for smoking cessation. Cochrane Database Syst Rev. 2019;9:CD013183. doi:10.1002/14651858.cd013183.pub2

5. Tan J, Zhao L, Chen H. A meta-analysis of the effectiveness of gradual versus abrupt smoking cessation. Tob Induc Dis. 2019;17(February). doi:10.18332/tid/100557

6. Etter J, Huguelet P, Perneger T, Cornuz J. Nicotine gum treatment before smoking cessation. Arch Intern Med. 2009;169:1028-1034. doi:10.1001/archinternmed.2009.12

7. Hughes JR, Solomon LJ, Livingston AE, Callas PW, Peters EN. A randomized, controlled trial of NRT-aided gradual vs. abrupt cessation in smokers actively trying to quit. Drug Alcohol Depend. 2010;111(1-2):105-113. doi:10.1016/j.drugalcdep.2010.04.007

8. Lindson-Hawley N, Banting M, West R, Michie S, Shinkins B, Aveyard P. Gradual Versus Abrupt Smoking Cessation: A Randomized, Controlled Noninferiority Trial. Ann Intern Med. 2016;164(9):585-592. doi:10.7326/m14-2805

9. West R, Hajek P, Stead L, Stapleton J. Outcome criteria in smoking cessation trials: proposal for a common standard. Addiction. 2005;100(3):299-303.

CONFLICTS OF INTEREST

The authors have completed and submitted the ICMJE Form for Disclosure of Potential Conflicts of Interest and none was reported.

FUNDING

N. Lindson is employed by the Cochrane Tobacco Addiction Group at the University of Oxford. The group is funded by an NIHR Infrastructure Grant. The views and opinions expressed therein are those of the authors and do not necessarily reflect those of the Systematic Reviews Programme, NIHR, NHS, or the Department of Health and Social Care. 